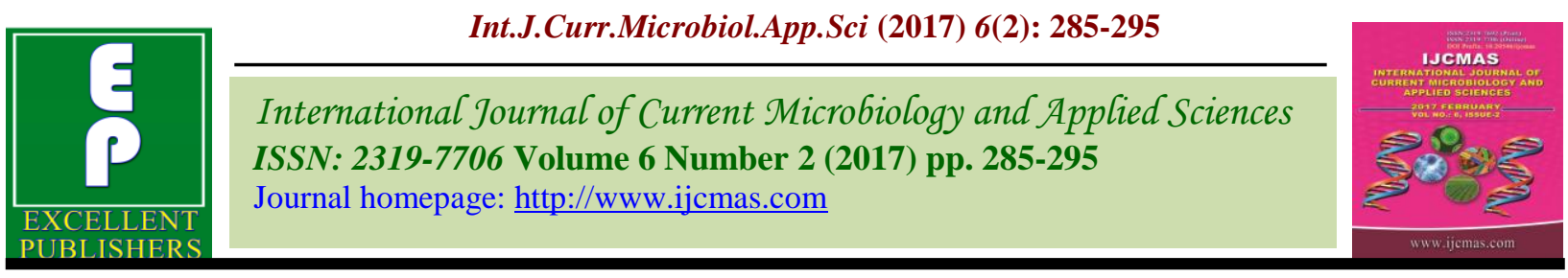

Original Research Article

http://dx.doi.org/10.20546/ijcmas.2017.602.034

\title{
Characterization of Reducing Sugars of Red Beet (Beta vulgaris L.) during Cold Storage through Statistical Modeling
}

\author{
Venkata Satish Kuchi $^{1}$ *, D. Ramesh ${ }^{2}$, S. Chakrabarty ${ }^{1}$ and R.S. Dhua ${ }^{1}$ \\ ${ }^{1}$ Department of Postharvest Technology of Horticultural Crops, Faculty of Horticulture, \\ Bidhan Chandra Krishi Viswavidyalaya, Mohanpur, Nadia, West Bengal - 741252, India \\ ${ }^{2}$ Department of Agricultural Statistics, Faculty of Agriculture, Bidhan Chandra Krishi \\ Viswavidyalaya, Mohanpur, Nadia, West Bengal - 741252, India \\ *Corresponding author
}

\begin{tabular}{|c|c|}
\hline & A B S T R A C T \\
\hline $\begin{array}{l}\text { Moisture content, } \\
\text { Multiple Linear } \\
\text { Regression, } \\
\text { Reducing sugars, } \\
\text { Run test, Shapiro- } \\
\text { Wilk's test. }\end{array}$ & \multirow{3}{*}{$\begin{array}{l}\text { Formation of reducing sugars during low temperature storage of red beet is } \\
\text { detrimental for processing, consumption as vegetable and easily deteriorated when } \\
\text { exposed to high temperatures. Most of the analytical methods are time consuming, } \\
\text { cost effective and laborious. So, assessing internal red beet quality through statistical } \\
\text { methods is alternative as mathematical modeling does not take error in to } \\
\text { consideration. These equations contain few parameters and the storability of the } \\
\text { product could be predicted before keeping it for storage based on the dependent } \\
\text { parameters. An attempt was made by employing Multiple Linear Regression and } \\
\text { paired T-test to predict the formation of reducing sugars on dependent variables like } \\
\text { moisture content and total soluble solids. Further, the results were confirmed by } \\
\text { Shapiro-Wilk's and Run tests. Regression analysis explained that reducing sugars } \\
\text { were significantly influenced by selected variables; about } 89.5 \text { percent }\left(\mathrm{R}^{2}=0.895\right) \text {. } \\
\text { There was non-significant difference between actual (lab) and predicted (model) } \\
\text { reducing sugars as per paired t-test. }\end{array}$} \\
\hline Article Info & \\
\hline $\begin{array}{l}\text { Accepted: } \\
\text { 12 January } 2017 \\
\text { Available Online: } \\
\text { 10 February } 2017\end{array}$ & \\
\hline
\end{tabular}

\section{Introduction}

Beet root or red beet (Beta vulgaris L.) is a root vegetable belongs to family Chenopodiaceae. Its wide utilization as salad, cooked vegetable, juice, pickle and in canning encouraged Indian growers to extend the area of cultivation. It has many nutritive properties and the ability of coloured compounds (betalains) with antiradical properties which improves quality of human blood and revives from stress based disorders (Pedreno and Escribano, 2000; Kugler et al., 2007) draws attention of consumers to use it in cuisine
(Kavitha et al., 2014). It's harvesting period extents from January to first week of March. According to econometric analysis at different vegetable markets of West Bengal, the price of vegetables grown in winter was at peak in off season. With the advancement in postharvest technology during past two decades and easy storability of red beet, a deviation from traditional storage had enabled growers and traders to stock in cold storage for 6-8 months (Sealand, 1991). Various physiological processes such as transpiration 
and respiration change its biochemical quality during long term storage of red beet. By reducing the storage temperatures to below 4 ${ }^{\circ} \mathrm{C}$, there is a decrease in respiration rate substantially (Dexter et al., 1969), but there is increase in reducing sugar with the loss of sucrose content (Wyse, 1978). Decrease in the beet quality is attributed to reduction of sucrose levels and increase in the reducing sugars (mainly invert sugars: glucose, fructose and raffinose) (Rosenkranz et al., 2001; Kenter and Hoffman, 2009). Sucrose is the most important respiratory substrate and $70-80 \%$ of it is lost during respiration. During long term cold storage of beet physiological weight loss is observed as a result of transpiration and respiration (Wyse, 1978). This is due to consumption of available moisture during substrate (sugars) break down. There is linear correlation between loss in moisture and increase in total soluble solids (TSS) of beet. If the produce is kept for long term storage, transpiration is high in the beet roots and water loss interferes with total soluble solids, decrease in sugar content and accumulation of reducing sugars (Jaggard et al., 1998). Formation of reducing sugars during low temperature storage is detrimental for processing, consumption as vegetable and easily deteriorated when exposed to high temperatures. Intensive research programmes were carried in European countries like Germany and Sweden to establish various factors effecting quality of beet and sugar losses during storage (Vukov and Hangyal, 1985). Most of the analytical methods are time consuming, costly and laborious. So, assessing internal red beet quality through statistical methods is alternative as mathematical modeling does not take error in to consideration. These equations contain few parameters and the storability of the product could be predicted before keeping it for storage. Multiple Linear Regression (MLR) analysis is a tool for predicting the value of a dependent variable by incorporating a number of independent variables simultaneously for an effective selection of dependent component characters. Relationships may be nonlinear, independent variables may be quantitative or qualitative, and one can examine the effects of a single variable or multiple variables with or without the influence of other variables taken into account (Cohen et al., 2003). Therefore, an experiment was initiated to forecast the reducing sugars based on moisture content and total soluble solids.

\section{Materials and Methods}

Roots of red beet were obtained from local cold storage (Amiyo Prabha Das multipurpose cold storage), Hoogly district of West Bengal (Figure 1-7). Nearly 50 tonnes of red beet was stored every year in the cold storage. Red beet with elongated shapes transpires more rapidly than globe shaped ones (Gaweda, 2006). So, local cultivar with globe shaped and medium sized red beets which reached harvest maturity were selected for the experiment. They were washed; air dried in shade and packed in jute bags with polythene lining. They were subjected to low temperature of $3 \pm 1{ }^{\circ} \mathrm{C}$ and relative humidity of $90-95 \%$. Twenty samples were collected from the cold storage randomly from different lots at monthly intervals. They were analyzed for chemical parameters in the laboratory of department of postharvest technology during the year 2013 to 2014 .

\section{Biochemical analysis}

Among chemical parameters; Total Soluble Solids (TSS) was analyzed by using an Abbe refractometer (Milton Roy Co., CA and USA), moisture content (MC) and reducing sugars (RS) were examined according to methodologies suggested by Ranganna (1986). 


\section{Statistical Analysis}

\section{Multiple Linear Regression (MLR)}

MLR analysis is the tool available to dependent variable in a simpler and comprehensive manner (Tabachnick and Fidell, 2001). For the estimation of reducing sugars, MC (\%), TSS ( ${ }^{\circ}$ Brix) and storage duration (days) are considered as explanatory variables in the present study. The multiple regression model employed here is the extension of simple regression equation such as given below,

$\mathrm{Y}=\mathrm{a}+\mathrm{bx}$

Where,

$\mathrm{Y}=$ dependent variable;

$\mathrm{a}=$ intercept;

$\mathrm{b}=$ the slope of the regression line or the amount of change produced in $\mathrm{Y}$ by a unit change in $\mathrm{x}$;

$\mathrm{x}=$ independent variable

The general form of multiple regression model in which more than one independent variables is included is given by,

$\mathrm{Y}=\mathrm{b}_{0}+\mathrm{b}_{1} \mathrm{x}_{1}+\mathrm{b}_{2} \mathrm{x}_{2}+\ldots \ldots \ldots+\mathrm{b}_{\mathrm{k}} \mathrm{x}_{\mathrm{k}}+\mathrm{e}$

The dependent variable $\mathrm{Y}$ is now regarded as a function of $\mathrm{k}$ independent variables $\left(\mathrm{x}_{1}, \mathrm{x}_{2}\right.$, ....., $\left.x_{k}\right)$. The coefficients $b 1$ to $b_{k}$ are referred to as the regression coefficients which in fact determine the contribution of the independent variables in the equation and $b_{0}$ is the $y$ intercept. The random error term (e) that is a random variable assumed to be normally and independently distributed between a mean of zero and a standard deviation of $\sigma$ that is added to make the model probabilistic. To determine the usefulness of the entire regression model as how well a linear model fits a set of data the multiple coefficient of determination $\left(\mathrm{R}^{2}\right)$ was used.

$\mathrm{R}^{2}=\mathrm{SSR} / \mathrm{SST}$ Where, $\mathrm{SSR}=$ regression sum of square or explained variability

$\mathrm{SST}=$ total sum of square or total variability

To know if the regression as a whole is significant or it was due to chance only, F-test was used.

$\mathrm{F}=\frac{\mathrm{MSR}}{\mathrm{MSE}}=\frac{\mathrm{R}^{2} / \mathrm{k}}{\left(1-\mathrm{R}^{2}\right)_{\mathrm{n}-\mathrm{k}-1}}$

Where,

MSR = mean square due to regression

$\mathrm{MSE}=$ mean square due to error

With $\mathrm{F}$ distribution having $\mathrm{k}$ numerator degrees of freedom $(\mathrm{k}=$ number of independent variables) and n-k-1 denominator degrees of freedom, F-test was used in the hypothesis test to determine whether there was a significant relationship among the dependent variable $\mathrm{Y}$ and all the independent variable involved in the equation (Stevens, 2002).

Paired t- test It is used to test for significant difference of means of two samples. When $\mathrm{n}_{1}=\mathrm{n}_{2}=\mathrm{n}$ and the two samples are not independent but the sample observations are paired together, then this test is applicable (Kanji, 2006). Let $\left(x_{i}, y_{i}\right), i=1, \ldots, n$ be a random sample from a bivariate normal population with parameters $\left(\mu_{1}, \mu_{2}, \sigma_{1}{ }^{2}, \sigma_{2}{ }^{2}, \rho\right)$. Let $\mathrm{d}_{\mathrm{i}}=\mathrm{x}_{\mathrm{i}}-\mathrm{y}$

$$
\begin{array}{ll}
H_{0}=\mu_{1}-\mu_{2}=\mu_{0} ; & \text { Test } \quad \text { statistic: } \\
t=\frac{\bar{d}-\mu_{0}}{s / \sqrt{n}} \square t_{n-1} ; & \text { Where } \bar{d}=\frac{1}{n} \sum_{i=1}^{n} d_{i} ;
\end{array}
$$


$s^{2}=\frac{1}{n-1} \sum_{i=1}^{n}\left(d_{i}-\bar{d}\right)^{2}$

Shapiro - Wilk test Normality of the residuals can be tested by Shapiro - Wilk test. In this, data arranged in non - decreasing sequence and is designated by $\mathrm{e}_{(1)}, \mathrm{e}_{(2)}, \mathrm{e}_{(3)} \ldots \mathrm{e}_{(\mathrm{n})}$. The required test statistic $\mathrm{W}$ is defined as

$$
\begin{aligned}
& W=S^{2} / b ; \quad \text { where } b=\sum_{i=1}^{n}\left(e_{i}-\bar{e}\right)^{2} ; \\
& S^{2}=\sum a(k)[e(n+1-k)-e(k)] .
\end{aligned}
$$

The parameter $\mathrm{k}$ takes the values, $\mathrm{K}=\mathrm{n} / 2$ (when data ' $\mathrm{n}$ ' is even); $\mathrm{k}=(\mathrm{n}-1) / 2$ when $\mathrm{n}$ is odd. The values of co-efficient "a (k)" for different values of $\mathrm{n}$ and $\mathrm{k}$ are given in Shapiro - Wilk table. The nonsignificant value is shown to be normality of the residuals (Shapiro-Wilk, 1965).

Run test Run test is used for examining whether a set of observations constitutes a random sample from an infinite population. Test for randomness is of major importance because the assumptions underlie statistical inference. In addition, tests for randomness are important for time series analysis (Sidney and Castellan, 1988).

$\mathrm{H}_{0}$ : Sample values come from random sequence

Test statistic: let $\mathrm{r}$ be the number of runs. For finding number of runs, observations are listed in their order of sequence. Each observation denoted by a ' + ' sign if it is more than the previous observation and by a '-' sign if it is less than the previous observation. $r$ is the sum of ' + ' and '-'.

When sample size is more than 25, then critical value $r_{c}$ can be obtained using a normal distribution approximation.
The critical values for two sided test at 5\% level of significance are

$\mathrm{r}_{\mathrm{c}}($ lower $)=\mu-1.96 \sigma ; \quad \mathrm{r}_{\mathrm{c}}$ (upper) $=\mu+$ $1.96 \sigma$;

Where $\mu=\frac{2 n-1}{3}$ and $\sigma=\sqrt{\frac{16 n-29}{90}}$

Decision is based on, $\mathrm{r}_{\mathrm{c}}$ (lower) $\leq \mathrm{r} \leq \mathrm{r}_{\mathrm{c}}$ (upper); then accept $\mathrm{H}_{0}$.

\section{Results and Discussion}

The details of the changes in the biochemical parameters and prediction of reducing sugars with statistical modeling for different storage periods were discussed in the following subheadings. Before applying the statistical model, the selected variables were subjected to descriptive statistics which gives basic idea on nature of variables. The variables were studied individually at monthly intervals to know the pattern of variation.

\section{Biochemical parameters}

TSS An increase in TSS was recorded during storage of beetroot for the first 60 days (Table $1)$. The increment was $3.4 \%$ with $\mathrm{CV}(\%)$ at 60 days was 3.14. There was a decrease in TSS from 60 days to 90 days, though it was only $0.7 \%$ and from 90 to 120 days the increment was $0.9 \%$. An overall raise $(4.21 \%)$ from beginning of the storage to end of storage of red beet could be observed. Similar trend was observed by Gaweda (2006) was observed while working on red beetroot quality with different storage conditions. Vitti et al. (2005) reported same trend but the difference in TSS from initial to final storage conditions was only $1 \%$ during cold storage of minimally processed beetroot. The final increase in soluble solids might be due to decrease in moisture content and increase in 
dry weight of the stored product (ZwartRoodzant, 1989; Kaur, 2014; Gaweda, 2006).

Moisture content (MC) There was a decrease in the MC during the storage of red beet (Table 1) and the difference from initial to final storage period is (13.4\%). Initial decrement of roots stored from 30 days to 60 days period was highest $(3.8 \%)$. These findings were in line with the reports from Gaweda (2006) on cold storage of red beet and Hailu et al. (2012) cold storage of banana. Decrease in MC might be due to liberation of heat and gaseous exchange of the produce as a result of metabolic processes like transpiration and respiration (Paull, 1999 and Hailu, 2014).

Reducing sugars (RS) showed an increasing trend during 180 days of storage. Overall elevation of reducing was $4.05 \%$ (Table 1). The increment in RS was mainly due to breakdown of sucrose by acid invertase. Almost $70-80 \%$ losses in sucrose were observed by Wyse (1970) due to respiration. Findings of Kenter and Hoffmann (2009) strengthen the above findings while working on quality of beet during storage. They also stated that formation of raffinose during storage causes deterioration in quality.

Multiple Linear Regression (MLR) RS were regressed on MC, TSS and duration of storage and estimated parameters were given in table 2. Regression analyses showed that all the components contributing to reducing sugars were negatively affected except for storage duration. All the variables have significant effect on dependent variables such as MC and TSS. Dahal and Routray (2011) applied MLR to predict yield of paddy by taking soil variables like soil reaction, organic matter, total nitrogen, phosphorus, potassium and soil texture. Similar prediction studies were prepared by Attua (2008) and Hamjah (2014) and estimated carbon stock and crop production respectively.
F ratio was significant (Table 2) indicating the overall explanatory power of the equation and regression line explaining about 89.5 percent $\left(\mathrm{R}^{2}=0.895\right)$ variations in reducing sugars by independent variables taken together all of these coefficients were significant (t-value in parentheses) as shown in table 3.

From table 3, fitted regression was calculated as below

\section{Equation 1}

\section{$\mathrm{RS}=27.894-0.261 *$ Moisture content -} $0.079 *$ TSS $+0.005 *$ Days

$\left(\mathrm{R}^{2}=0.895\right)$

Shapiro Wilk and Run Test Normality and randomness of residual assumptions were tested by Shapiro Wilks and Run test respectively. From table 4, it was clear that residuals were distributed normally and independently as probability values of both tests were non- significant. Shapiro Wilk test was further verified by normal probability and histogram plot (Figure 8). So, it was confirmed that selected model was normally distributed and there were no extreme residuals.

Two samples were randomly selected for each storage interval for both TSS and MC from 140 samples for each parameter. Prediction of reducing sugar (RS) was made by the regression equation (stated earlier in equation $1)$. The predicted values were depicted in table 5. Actual and predicted values for RS were given in table 5 and could be concluded that the values were close.

Furthermore, a paired samples t-test approach was used to compare the RS values predicted by using RS-(MC, TSS and SD) model and $\mathrm{RS}$ value measured by laboratory test. The RS values of both predicted (from model) and determined (from lab) were depicted in table. 
Table.1 Descriptive statistics of biochemical parameters during cold storage of red beet

\begin{tabular}{|c|c|c|c|c|c|c|}
\hline DAYS & Parameters & Mean & Standard Deviation & CV\% & Minimum & Maximum \\
\hline \multirow{3}{*}{$\mathbf{0}$} & RS (\%) & 4.74 & 0.41 & 8.67 & 4.1 & 5.7 \\
\hline & $\mathrm{MC}(\%)$ & 84.66 & 0.87 & 1.03 & 83.2 & 86 \\
\hline & TSS ( ${ }^{\circ}$ Brix) & 14.26 & 0.55 & 3.89 & 13.2 & 15.2 \\
\hline \multirow{3}{*}{30} & RS (\%) & 5.14 & 0.41 & 7.99 & 4.5 & 6.1 \\
\hline & $\mathrm{MC} \mathrm{( \% )}$ & 81.86 & 0.87 & 1.06 & 80.4 & 83.2 \\
\hline & TSS ( ${ }^{\circ}$ Brix) & 15.86 & 0.55 & 3.5 & 14.8 & 16.8 \\
\hline \multirow{3}{*}{60} & $\operatorname{RS}(\%)$ & 6.24 & 0.41 & 6.59 & 5.6 & 7.2 \\
\hline & $\mathrm{MC}(\%)$ & 78.06 & 0.87 & 1.11 & 76.6 & 79.4 \\
\hline & TSS ( ${ }^{\circ}$ Brix) & 17.66 & 0.55 & 3.14 & 16.6 & 18.6 \\
\hline \multirow{3}{*}{90} & $\operatorname{RS}(\%)$ & 7.94 & 0.41 & 5.18 & 7.3 & 8.9 \\
\hline & $\mathrm{MC}(\%)$ & 75.26 & 0.87 & 1.15 & 73.8 & 76.6 \\
\hline & TSS ( ${ }^{\circ}$ Brix) & 16.96 & 0.55 & 3.27 & 15.9 & 17.9 \\
\hline \multirow{3}{*}{120} & $\operatorname{RS}(\%)$ & 7.64 & 0.41 & 5.38 & 7 & 8.6 \\
\hline & MC (\%) & 74.06 & 0.87 & 1.17 & 72.6 & 75.4 \\
\hline & TSS ( ${ }^{\circ}$ Brix) & 17.86 & 0.55 & 3.11 & 16.8 & 18.8 \\
\hline \multirow{3}{*}{150} & RS (\%) & 8.23 & 0.38 & 4.6 & 7.6 & 8.9 \\
\hline & MC (\%) & 72.52 & 0.88 & 1.21 & 71.1 & 73.9 \\
\hline & TSS ( ${ }^{\circ}$ Brix) & 17.55 & 0.55 & 3.11 & 16.5 & 18.5 \\
\hline \multirow{3}{*}{180} & RS (\%) & 8.79 & 0.42 & 4.78 & 8.1 & 9.7 \\
\hline & MC (\%) & 71.2 & 0.93 & 1.3 & 69.7 & 72.8 \\
\hline & TSS ( ${ }^{\circ}$ Brix) & 18.47 & 0.55 & 2.96 & 17.4 & 19.4 \\
\hline \multirow{3}{*}{ Average } & RS (\%) & 6.95 & 1.52 & 21.89 & 4.1 & 9.7 \\
\hline & MC (\%) & 76.8 & 4.7 & 6.12 & 69.7 & 86 \\
\hline & TSS $\left({ }^{\circ}\right.$ Brix $)$ & 16.94 & 1.44 & 8.51 & 13.2 & 19.4 \\
\hline
\end{tabular}

MC- moisture content TSS- Total soluble solids RS- Reducing Sugar

Table.2 ANOVA for multiple regression

\begin{tabular}{|c|c|c|c|c|c|}
\hline & df & SS & MS & F-stat & P-value \\
\hline Regression & 3 & 288.479 & 96.159 & 387.499 & $<0.00$ \\
\hline Residual & 136 & 33.749 & 0.248 & & \\
\hline Total & 139 & 322.223 & & & \\
\hline
\end{tabular}

df- degree of freedom; SS-Sum of Square: MSS-Mean Sum of Squares

Table.3 Estimated parameters of linear regression model

\begin{tabular}{|c|c|c|c|c|}
\hline Variables & Coefficients & Standard Error & t Stat & P-value \\
\hline Intercept & 27.894 & 3.302 & 8.446 & $<0.00$ \\
\hline MC & -0.261 & 0.035 & -7.440 & $<0.00$ \\
\hline TSS & -0.079 & 0.005 & -15.012 & $<0.00$ \\
\hline Days & 0.005 & 0.003 & 2.034 & 0.044 \\
\hline
\end{tabular}

MC- moisture content; TSS- Total soluble solids 

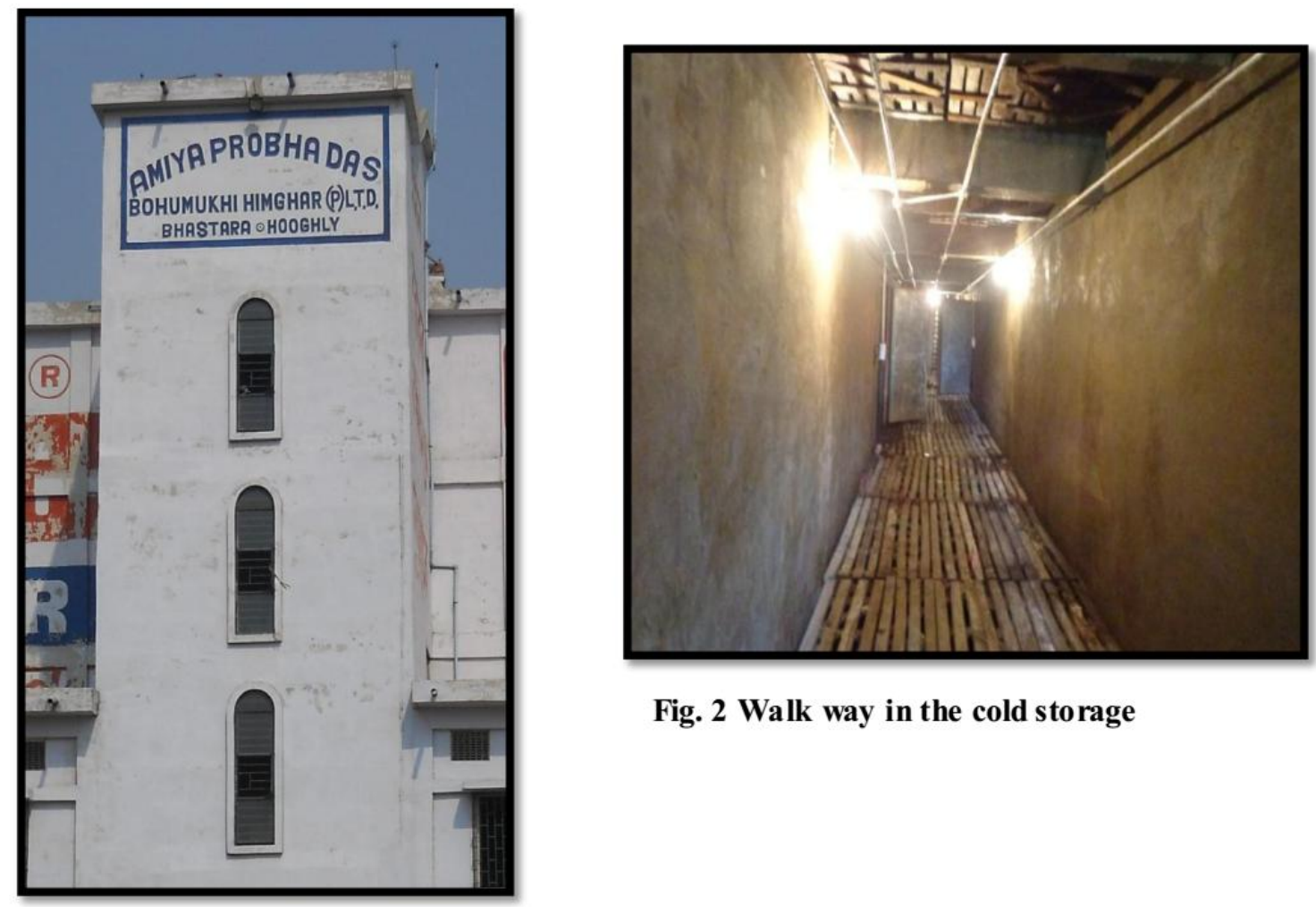

Fig. 2 Walk way in the cold storage

Fig. 1 Cold storage (view from outside)

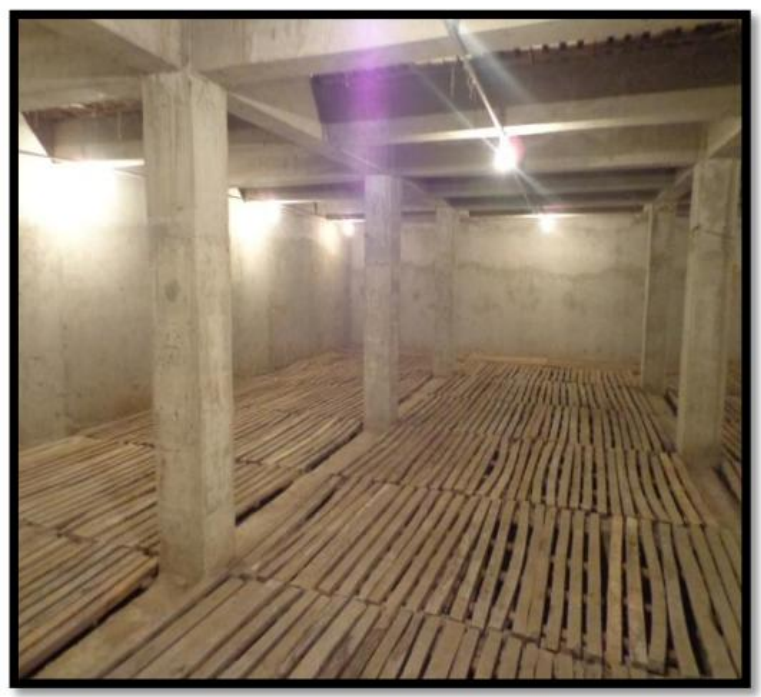

Fig. 3 Room in cold storage

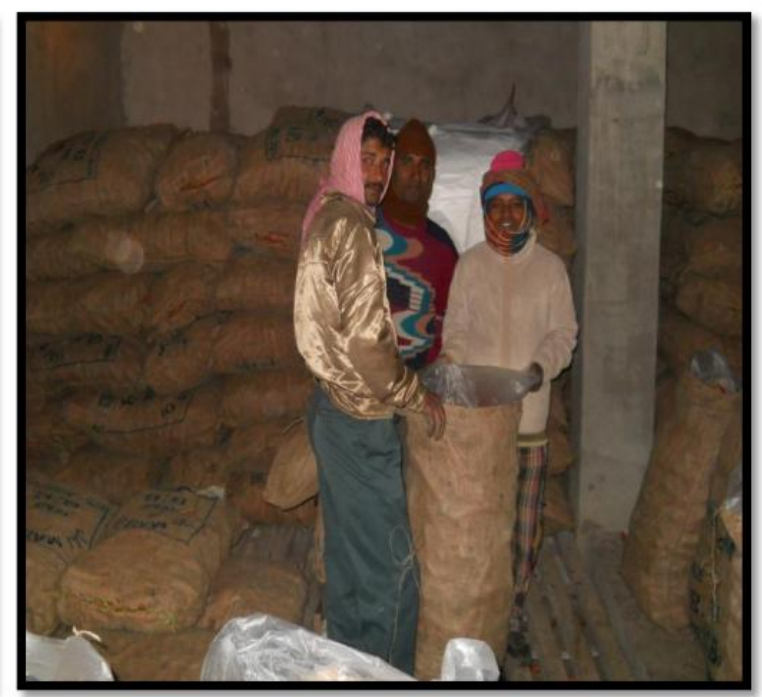

Fig. 4 Packaging of beetroot in cool store 


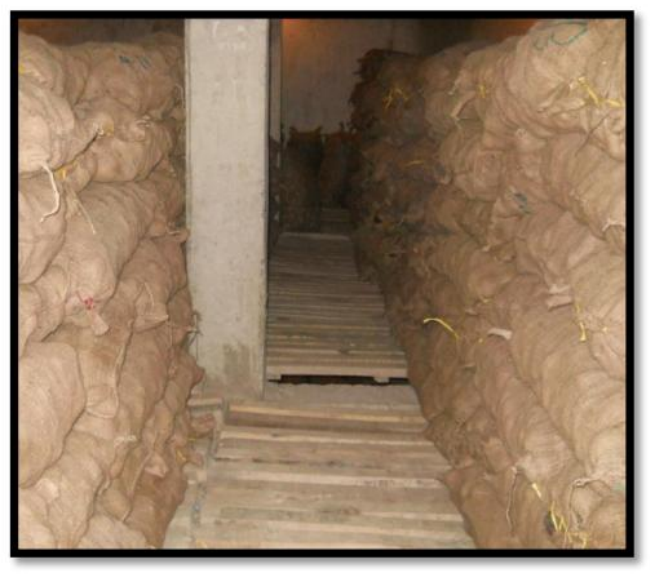

Fig. 5 Arrangement of packaged beet root

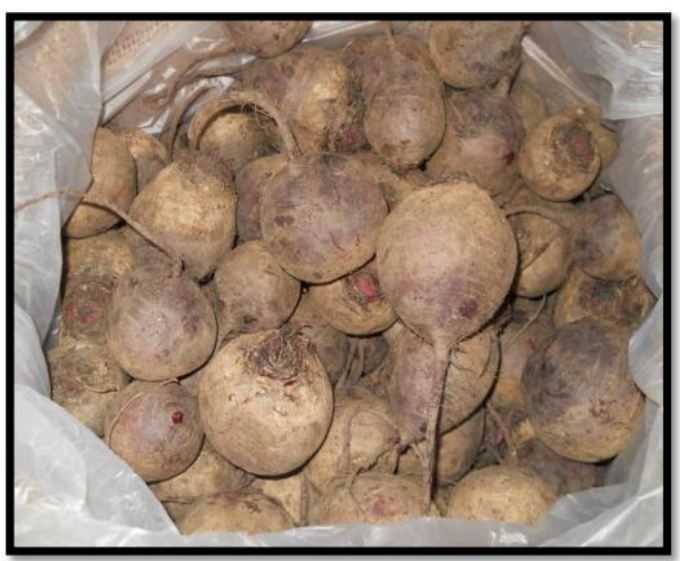

Fig. 6 Inner vie w of package
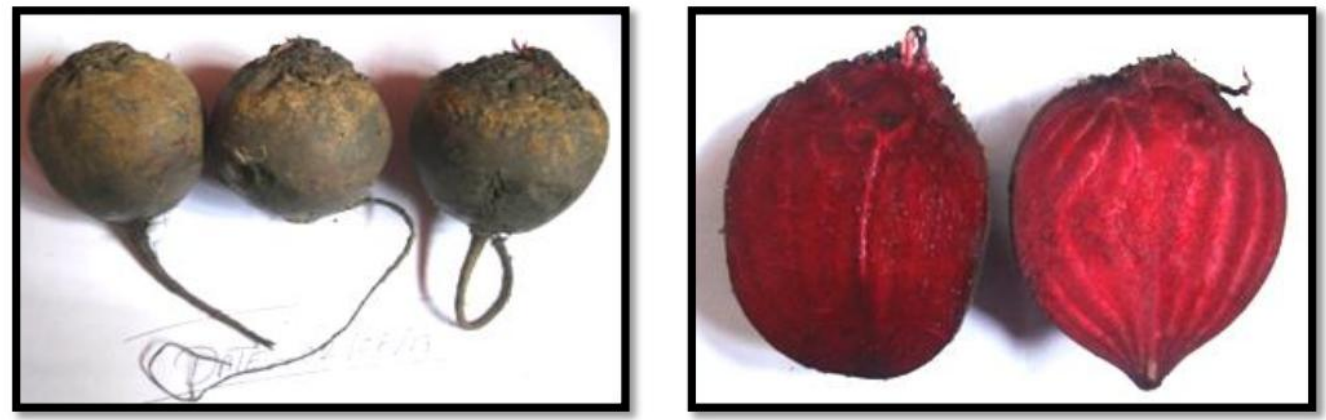

Fig. 7 Beet root 6 months after storage

Cross section

Fig.8 Probability plot and Histogram of residuals
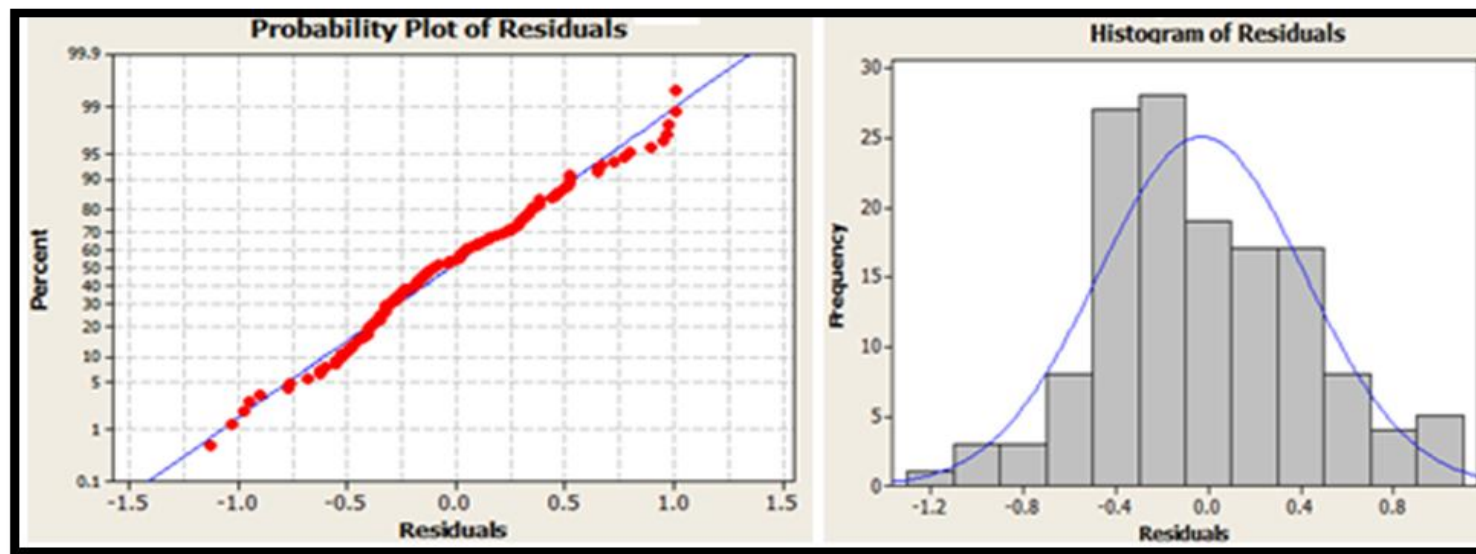

Now seoses

s 
Table.4 Test for normality and randomness of residuals

\begin{tabular}{|c|c|c|}
\hline \multirow{2}{*}{ Prob. Value of Residuals } & Shapiro Wilks Test & Run Test \\
\cline { 2 - 3 } & 0.132 & 0.077 \\
\hline
\end{tabular}

Table.5 Actual and predicted values of reducing sugars for randomly selected samples

\begin{tabular}{|c|c|c|c|c|}
\hline DAYS & MC & TSS & Actual RS & $\begin{array}{c}\text { Predicted RS for Randomly } \\
\text { Selected Samples }\end{array}$ \\
\hline 0 & 85.4 & 14.1 & 4.3 & 4.474 \\
\hline 0 & 84.8 & 14.5 & 4.6 & 4.592 \\
\hline 30 & 81.8 & 15.8 & 5.1 & 5.425 \\
\hline 30 & 81.0 & 15.9 & 5.5 & 5.618 \\
\hline 60 & 78.0 & 17.6 & 6.2 & 6.418 \\
\hline 60 & 79.4 & 16.6 & 6.4 & 6.148 \\
\hline 90 & 75.0 & 17.9 & 7.7 & 7.333 \\
\hline 90 & 74.5 & 16.7 & 7.3 & 7.557 \\
\hline 120 & 72.9 & 17.0 & 8.1 & 8.119 \\
\hline 120 & 72.6 & 18.0 & 8.2 & 8.113 \\
\hline 150 & 72.3 & 18.5 & 8.0 & 8.332 \\
\hline 150 & 71.1 & 17.7 & 8.8 & 8.699 \\
\hline 180 & 70.3 & 18.5 & 9.1 & 9.020 \\
\hline 180 & 69.7 & 18.6 & 9.3 & 9.163 \\
\hline
\end{tabular}

MC- moisture content TSS- Total soluble solids RS- Reducing Sugar

The paired samples t-test results demonstrate that the RS values predicted with the RS(MC, TSS and SD) model were not significantly different than that measured with laboratory tests as the calculated value 0.972 was lesser than tabulated value 2.160.

In conclusion, biochemical analysis suggested that there were changes in selected parameters i.e., total soluble solids, moisture content and reducing sugars during cold storage of red beet. Predicted model obtained from multiple linear regression suggested that the laboratory values and the predicted values for reducing sugars were non-significantly different. So far, statistical modeling was used to forecast yield, weather and soil fertility. In conclusion, such models could be applied for various 
postharvest quality attributes to predict storage life and changes that occur in produce.

\section{Acknowledgements}

Authors convey gratitude to 'Directorate of Agricultural Marketing, West Bengal' for funding the project and 'Directorate of Research, Bidhan Chandra Krishi Viswavidyalaya' for providing necessary research facilities. Mr. Narayan Das, Managing director of 'Amiyaprobha Das' multipurpose cold storage and his staff are heartly thanked for their continuous and sincere support throughout the project.

\section{References}

AOAC. (15th ed.) 1990. Official methods of analysis. Association of Official Analytical Chemists, Washington DC.

Attua, E.M. 2008. Using Multiple Linear Regression Techniques to Quantify Carbon Stocks of Fallow Vegetation in the Tropics. West Afr. J. App. Ecol., 12(1): 72-79.

Cohen, J., Cohen, P., West, S.G. and Aiken, L.S. (3rd ed.) 2003. Applied multiple regression/correlation analysis for the behavioral sciences, Lawrence Erlbaum Associates, Mahwah, NJ.

Dahal, H. and Routray, J.K. 2011. Identifying associations between soil and production variables using linear multiple regression models. The $J$. Agric. Environ., 12: 27-37.

Dexter, S.T., Frakes, M.G. and Wyse, R.E. 1969. Damage to sugarbeet roots from various degrees of wilting at various temperatures. J. Am. Soc. Sugar Beet Technol., 15: 480-488.

Gaweda, M. 2006. The effect of storage conditions on red beetroot quality. Veg. Crops Res. Bull., 65: 85-94.

Hailu, M., Workneh, T.S. and Belew, D. 2014. Effect of packaging materials on shelf life and quality of banana cultivars (Musa spp.).J. Food Sci. Technol., 51(11): 2947-2963.

Hailu, M., Workneh, T.S. and Belew, D. 2012. Effect of packaging materials on the quality of banana cultivars. Afr. J. Agric. Res., 7(7): 1226-1237.

Hamjah, M.A. 2014. Climatic effects on major oilseed crops production in Bangladesh: An application of multiple regression model. J. Econ. Sustainable Dev., 5(19): 45-59.

Jaggard, K., Dewar, A. and Pidgeon, J. 1998. The relative effects of drought stress and virus yellow on the yield of sugar beet in the UK, 1980-1995. J. Agric. Sci., 103: 337-343.

Kanji, G.K. 2006. 100 Statistical tests. Sage publications, New Delhi.

Kavitha, R., Ravichandran, P., Saw, N.M.M.T., Gabr, A.M.M., Abdel, R.R., Ahmed, R., Knorr, D. and Smetanska, I. 2014. Effects of different encapsulation agents and drying process on stability of betalains extract. J. Food Sci. Technol., 51(9): 2216-2221.

Kenter, C. and Hoffmann, C.M. 2009. Changes in the processing quality of sugar beet (Beta vulgaris L.) during long-term storage under controlled conditions. Int. J. Food Sci. Tech., 44(5): 910-917.

Kugler, F., Stintzing, F.C. and Carle, R. 2007. Evaluation of the antioxidant capacity of betalainic fruits and vegetables. $J$. Appl. Bot. Food Qual., 81(1): 69-76.

Kujala, T.S., Loponen, J.M., Klika, K.D. and Pihlaja, K. 2000. Phenolics and betacyanins in red beetroot (Beta vulgaris) root: distribution and effect of cold storage on the content of total phenolics and three individual compounds. J. Agric. Food Chem., 48(11): 5338-5342.

Mendham, J., Denney, R.C., Barnes, J.D. and Thomas, M. 2000. Vogel's Textbook of 
Quantitative Chemical Analysis, Pearson Education Ltd., England.

Paull, R. 1999. Effect of temperature and relative humidity on fresh commodity quality. Postharvest Biol. Technol., 15(3): 263-277.

Pedreno, M.A. and Escribano, J. 2000. Studying the oxidation and antiradical activity of betalain from beetroot. $J$. Biol. Educ., 35: 49-59.

Ranganna, S. (2nd ed.) 1986. Handbook of analysis and quality control for fruit and vegetable products,. Tata McGraw Publ Co. Ltd., New Delhi.

Rosenkranz, H., Vogel, R., Greiner, S. and Rausch, T. 2001. In wounded sugar beet (Beta vulgaris L.) tap-root, hexose accumulation correlates with the induction of a vacuolar invertase isoform. J. Exp. Bot., 52(365): 23812385

Sea Land. 1991. Shipping Guide to Perishables. Sea Land Services, Iselim, New Jersey.

Shapiro, S.S. and Wilk, M.B. 1965. An analysis of variance test for normality (complete samples). Biometrika, 52: 591-611.

Sidney, S. and Castellan, J.N. 1988. Nonparametric statistics for the behavioral sciences. McGraw-Hill, New York.

Stevens, J.P. $\quad\left(4^{\text {th }}\right.$ ed. $)$ 2002. Applied multivariate statistics for the social sciences, Mahwah, NJ, Lawrence Erlbaum Associates.

Tabachnick, B.G. and Fidell, L.S. ( $4^{\text {th }}$ ed.) 2001. Using multivariate statistics. Needham Heights, MA: Allyn \& Bacon.

Vitti, M.C.D., Yamamoto, L.K., Sasaki, F.F., Aguila, J.S.D., Kluge, R.A. and Jacomin, A.P. 2005. Quality of minimally processed beet roots stored in different temperatures. Brazil Archives Biol. Technol., 48(4): 503-510.

Vukov, K. and Hangyal, K. 1985. Sugar beet storage. Sugar Technol. Rev., (12): 143265.

Wyse, R.E. 1978. Effect of low and fluctuating temperatures on the storage life of sugar beets. J. Am. Soc. Sugar Beet Technol., 20(1): 33-42.

\section{How to cite this article:}

Venkata Satish Kuchi, D. Ramesh, S. Chakrabarty and Dhua, R.S. 2017. Characterization of Reducing Sugars of Red Beet (Beta vulgaris L.) during Cold Storage through Statistical Modeling. Int.J.Curr.Microbiol.App.Sci. 6(2): 285-295. doi: http://dx.doi.org/10.20546/ijcmas.2017.602.034 